\title{
GÉNERO Y PARTICIPACIÓN SOCIAL EN SALUD DESDE LA EXPERIENCIA CIUDADANA EN EL SALVADOR
}

\section{GENDER AND SOCIAL PARTICIPATION IN THE HEALTH FIELD FROM THE CIVIC EXPERIENCE IN EL SALVADOR}

LUZMILA TATIANA ARGUETA MONTERROZA ${ }^{1}$

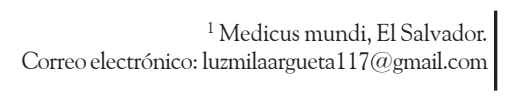

Resumen:

Los procesos de participación social en salud están vinculados a la historia política, cambios económicos y cambios sociales de cada sociedad. La relación entre Estado y Ciudadanía está mediada por determinantes sociales, una de ellas es el género, con implicancias en la construcción de desigualdades. En el ámbito de la participación social en salud, se requiere una valoración de la medida en que las acciones y rasgos asociados a los hombres y las mujeres tienen mayor o menor credibilidad o reconocimiento social. El estudio tiene como objetivo caracterizar, con un enfoque de género, los procesos de participación social en salud desde la experiencia y perspectiva de la ciudadanía en dos micro redes de servicios de salud en El Salvador en el año 2015. El estudio es de tipo cualitativo exploratorio, se realizaron 29 entrevistas semi-estructuradas en 9 municipali- 
dades, a hombres y mujeres dirigentes sociales de las comunidades de dos micro redes de servicios de salud del Departamento de Morazán en El Salvador, Centro América. Entre los resultados se obtuvieron percepciones y experiencias comparadas que evidencian desigualdades de género en el acceso, condiciones y tipos de espacios disponibles para la participación, en donde se reproducen y refuerzan roles de género tradicionales. Sin embargo, se evidencian liderazgos femeninos sobresalientes vinculados a la formación política, organizativa y de género. Además, se revelan dificultades en la autonomía para los procesos participativos y para espacios horizontales. A manera de conclusión, se plantea que la equidad en mecanismos y en las oportunidades de participación requiere ser revisada desde el punto de vista de género; organizaciones no gubernamentales han jugado un papel positivo en el empoderamiento y participación de las mujeres en las localidades estudiadas, donde la formación en género ha sido fundamental.

Palabras clave: participación social en salud, género, empoderamiento de mujeres, liderazgo femenino, procesos participativos

\section{Abstract:}

The process of social participation in the health field is linked to the political history, economic and social changes of each 
society. The relationship between the State and the exercise of citizenship are mediated by social determinants, with implications for the social construction of gender-based inequalities. The objective of the study is to characterize, with a gender perspective, the process of social participation from the experience and perspective of citizens. The study was carried out in 2015 and located in El Salvador, Central America. The study is a qualitative exploratory study conducted in 9 municipalities and involves male and female social leaders from the communities of two health networks: Corinto and Perquín, of the Department of Morazán in El Salvador, Central America. The sample included 29 semi-structured interviews. Results of the study include social leader's perceptions and experiences, revels gender inequalities in access, social conditions, and forms of participation available for men and women also shows that traditional gender roles are reproduced and reinforced. However, there are outstanding female leaderships associated with political and gender training. Likewise, difficulties are exposed in maintaining autonomy and horizontal leadership. The study concluded that Gender Equity in mechanisms and opportunities to participate need to be reviewed, the non-governmental organizations have played a positive role in the empowerment and support of women for their involvement facilitating gender education and financial support. 
Keywords: social participation in health, gender, empowerment of women, female leadership, Central America

ReCEPCIÓN: 30 de NOVIEMBRE de 2020/ACEPTACIÓN: 17 DE FEBRERO DE 2021

\section{INTRODUCCIÓN}

En Salud Pública se vuelve cada vez más necesario com-

prender los fenómenos sociales que influyen en el proceso de construcción de la salud. La participación social es uno de estos fenómenos. Participar es tomar parte en "la intervención de la sociedad civil en la esfera de lo público" (Cunill, 2009). Esfera donde las mujeres han sido históricamente excluidas y subvaloradas, siendo discriminadas sistemáticamente por su condición de género. Menéndez habla de la participación como el proceso por el cual los individuos y las familias asumen responsabilidades de bienestar propio y los de la colectividad y mejoran la capacidad de contribuir a su propio desarrollo económico y comunitario (Menéndez, 1995, pp. 7-37). Responsabilidades que recaen predominantemente sobre las mujeres, dentro y fuera del hogar, agudizando las desigualdades sociales estructurales que ponen en situación de desventaja a la mujer y manifestándose más evidente pero no exclusivamente en estratos socioeconómicos bajos (García-Calvente, Mateo-Rodríguez y Maroto Navarro, 2004, pp. 83-92). 
El género, corresponde a una construcción social de roles y rasgos atribuidos al papel que juegan los hombres y las mujeres tanto en el ámbito público como en el ámbito privado. Estas atribuciones sociales determinan la organización de las relaciones sociales que frecuentemente tienden a ser jerárquicas y a atribuir mayor valor a lo masculino. En el ámbito de la participación social en salud, se requiere una valoración de la medida en que los estereotipos impuestos tiene mayor o menor credibilidad o reconocimiento social, como es el caso de la racionalidad, la fuerza y la facultad para tomar decisiones, asociados erróneamente solo a lo masculino y determinando de esta manera la distribución inequitativa de la posibilidad de tomar parte en la participación social en salud.

La política nacional de participación en salud de El Salvador impulsa la equidad y la no discriminación por género. Establece que "hombres y mujeres tendrán trato justo y equitativo, que significa reconocer y valorar de manera equilibrada el potencial de mujeres y hombres, así como las diferentes realidades, intereses y necesidades de salud" (Ministerio de Salud del Gobierno de El Salvador, 2012, pp. 53-85).

Para lograr una equidad de género, es necesario reconocer que existen inequidades que determinan oportunidades, acceso y control de los recursos; hace falta indagar cómo estas inequidades limitan la participación de mujeres y no les permiten acceder al poder. Lo que nos lleva a preguntarnos: ¿es diferente el proceso de participación social en salud para mujeres y hombres? y ien 
qué contextos se aprecian con mayor claridad estas diferencias? Este estudio es una aproximación cualitativa a los conceptos, mecanismos, significados y valores de la participación social en salud desde la perspectiva de la sociedad civil. Tiene como objetivo general, caracterizar con un enfoque de género los procesos de participación social en salud en la micro red de servicios de salud de Corinto y micro red de servicios de salud de Perquín en el departamento de Morazán. La zona donde se realizó el estudio tiene una trayectoria histórica en la participación social y organización comunitaria pre y post guerra civil de El Salvador desde los años setenta y ochenta. Ocho de los nueve municipios estudiados se asocian organizativamente con la estructura nacional del Foro Nacional de Salud (FNS), organización y movimiento social por el derecho a la salud.

Este artículo está orientado particularmente a exponer las limitantes encontradas para la participación de las mujeres y busca, además, ofrecer información orientativa para aquellas políticas públicas que aspiren a impulsar espacios comunitarios más inclusivos, donde las mujeres tengan voz y voto en la toma de decisiones para el cuidado y atención en salud.

\section{METOdOLOGÍA}

El diseño muestral fue de carácter teórico, estructural, definido por la residencia en las distintas áreas geográficas. Como criterio de conformación de la muestra se 
utilizó el sexo; se consideró la diversidad en nivel educativo, edad, cargos directivos o bases. La estrategia de muestreo fue en bola de nieve y se realizaron entrevistas a profundidad semi-estructuradas de duración entre $50 \mathrm{~min}$ y 2 horas, alcanzando saturación a las 29 entrevistas, 14 mujeres, 15 hombres.

Tabla 1: distribución de la muestra

\begin{tabular}{|c|c|c|c|}
\hline \multirow[b]{2}{*}{ Sexo } & \multirow[b]{2}{*}{ Nivel educativo } & \multicolumn{2}{|c|}{ Cargo } \\
\hline & & Directivo & No directivo \\
\hline \multirow{4}{*}{$\begin{array}{c}\text { Mujeres } \\
(3<35 \text { años, } 10>35 \text { años }<60 \text { años } \\
1>60 \text { años })\end{array}$} & Educación básica & 1 & 8 \\
\hline & Educación media & 3 & 1 \\
\hline & Educación superior & 0 & 1 \\
\hline & Total mujeres & 4 & 10 \\
\hline \multirow{4}{*}{$\begin{array}{c}\text { Hombres } \\
(4<35 \text { años, } 6>35 \text { años }<60 \text { años } \\
5>60 \text { años })\end{array}$} & Educación básica & 5 & 1 \\
\hline & Educación media & 0 & 3 \\
\hline & Educación superior & 3 & 3 \\
\hline & Total hombres & 8 & 7 \\
\hline \multicolumn{2}{|l|}{ Total } & 12 & 17 \\
\hline
\end{tabular}

Fuente: elaboración propia. 


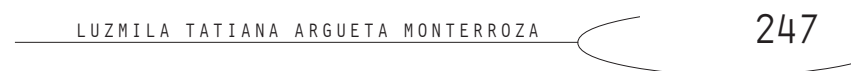

Las entrevistas fueron grabadas y transcritas en su totalidad. Se utilizó una libreta de campo y en la convivencia comunitaria se asistió a las reuniones abiertas convocadas. Se establecieron categorías en la guía de entrevista y a partir de la información recolectada surgieron sub categorías de análisis. Se identificaron patrones y además se segmentó la información por estratificación de la muestra para identificar similitudes y peculiaridades al hacer un análisis de contenido utilizando software Atlas-ti. Las personas participantes realizaron un consentimiento informado.

\section{RESULTADOS}

Los resultados han sido estructurados a partir de categorías establecidas en la guía de las entrevistas y las sub-categorías surgieron de la información recolectada desde el análisis de contenido y se encuentran divididas en los apartados siguientes, así: 


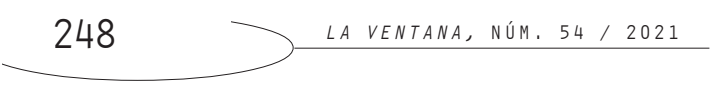

Tabla 2: Conceptos y formas de participación

\begin{tabular}{|c|c|c|}
\hline $\begin{array}{l}\text { Concepto y } \\
\text { formas }\end{array}$ & $\begin{array}{l}\text { Perfiles identificados } \\
\text { en relación con } \\
\text { conceptos y mecanismos }\end{array}$ & Citas Relacionadas \\
\hline $\begin{array}{l}\text { Colaboración } \\
\text { con programas } \\
\text { de salud }\end{array}$ & $\begin{array}{l}\text { Participación de tipo consul- } \\
\text { tiva. Es bastante transversal } \\
\text { en las personas, la colabora- } \\
\text { ción con la ejecución de pro- } \\
\text { gramas es una idea que está } \\
\text { presente en todas las perso- } \\
\text { nas. }\end{array}$ & $\begin{array}{l}\text { “...un comité de lactancia } \\
\text { materna, nos dieron la ca- } \\
\text { pacitación de como } \\
\text { aconsejar a las madres si } \\
\text { eran primerizas, todo eso } \\
\text { así. E04, Mujer de } 49 \text { años. }\end{array}$ \\
\hline $\begin{array}{l}\text { Desarrollo } \\
\text { social }\end{array}$ & $\begin{array}{l}\text { Los hombres se ven a sí mis- } \\
\text { mos como responsables del } \\
\text { desarrollo social como fruto } \\
\text { de la participación social. Es } \\
\text { muy frecuente en hombres con } \\
\text { largas trayectorias de parti- } \\
\text { cipación. }\end{array}$ & $\begin{array}{l}\text { "Estoy en diferentes acti- } \\
\text { vidades relacionadas con } \\
\text { el desarrollo de la comu- } \\
\text { nidad, entre ellas lo de } \\
\text { salud". E2, Hombre de } 73 \\
\text { años. }\end{array}$ \\
\hline $\begin{array}{l}\text { Derecho } \\
\text { ciudadano }\end{array}$ & $\begin{array}{l}\text { Personas con trayectorias lar- } \\
\text { gas de participación con for- } \\
\text { mación política y organizativa. } \\
\text { Especialmente se evidencia en }\end{array}$ & $\begin{array}{l}\text { "es un deber, es una res- } \\
\text { ponsabilidad... un dere- } \\
\text { cho es un compromiso de } \\
\text { cada uno de nosotros, yo }\end{array}$ \\
\hline
\end{tabular}




\begin{tabular}{|c|c|c|}
\hline & $\begin{array}{l}\text { militantes de partidos polí- } \\
\text { ticos y personas que han os- } \\
\text { tentado cargos en estructuras } \\
\text { políticas partidarias, con for- } \\
\text { mación de este tipo. }\end{array}$ & $\begin{array}{l}\text { así lo veo". E8, Hombre } \\
\text { de } 55 \text { años. }\end{array}$ \\
\hline Contraloría social & $\begin{array}{l}\text { Es más frecuente en mujeres } \\
\text { y solo es mencionada en los } \\
\text { municipios donde el FNS está } \\
\text { presente. Tiene muchas va- } \\
\text { riantes en cuanto a sus ac- } \\
\text { ciones, va desde la contraloría } \\
\text { al nivel local hasta interven- } \\
\text { ciones en la creación, formu- } \\
\text { lación y evaluación de políticas } \\
\text { públicas de salud a nivel na- } \\
\text { cional. }\end{array}$ & $\begin{array}{l}\text { "no era venir a poner el } \\
\text { dedo al personal, sino que } \\
\text { venir a hacer contraloría... } \\
\text { que usuarias tengan una } \\
\text { buena atención... ver que } \\
\text { los promotores estén tra- } \\
\text { bajando". E20, Mujer } 33 \\
\text { años. }\end{array}$ \\
\hline
\end{tabular}

Fuente: elaboración propia. 


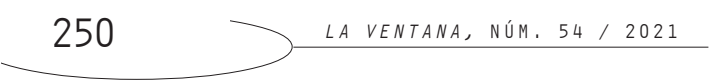

Tabla 3: Espacios de participación para mujeres y hombres

\begin{tabular}{|c|c|c|}
\hline Espacio encontrado & $\begin{array}{c}\text { Actividades de mayor } \\
\text { envergadura }\end{array}$ & $\begin{array}{c}\text { Perfil de } \\
\text { participantes }\end{array}$ \\
\hline $\begin{array}{l}\text { Foro Nacional de Salud } \\
\text { (FNS) }\end{array}$ & $\begin{array}{l}\text { Discusión y propuestas a } \\
\text { políticas públicas y leyes. } \\
\text { Movilizaciones y Capacita- } \\
\text { ciones. }\end{array}$ & Mujeres y Hombres \\
\hline $\begin{array}{l}\text { Micro red de Servicios de } \\
\text { Salud }\end{array}$ & $\begin{array}{l}\text { Se presentan planes de tra- } \\
\text { bajo de Centros de Salud. } \\
\text { Gestión de servicios. }\end{array}$ & Mujeres y Hombres. \\
\hline $\begin{array}{l}\text { Alianza Regional de Salud } \\
\text { (ARSAM) }\end{array}$ & $\begin{array}{l}\text { Aumentar su representati- } \\
\text { vidad con el objetivo de } \\
\text { lograr incidencia en políti- } \\
\text { cas públicas. }\end{array}$ & $\begin{array}{l}\text { Mujeres y Hombres } \\
\text { Coordinación mujeres }\end{array}$ \\
\hline $\begin{array}{l}\text { Comité de Contraloría } \\
\text { Social }\end{array}$ & $\begin{array}{l}\text { Levantamiento de datos de } \\
\text { satisfacción usuaria. Rendi- } \\
\text { ción de cuentas. }\end{array}$ & Mujeres y Hombres \\
\hline Comité Local de Salud & $\begin{array}{l}\text { Suplir falencias de Centro de } \\
\text { Salud. Colaboran dentro de } \\
\text { los programas de salud y } \\
\text { promoción de la salud. }\end{array}$ & $\begin{array}{l}\text { Mujeres y Hombres } \\
\text { De predominio } \\
\text { mujeres. }\end{array}$ \\
\hline $\begin{array}{l}\text { Asociaciones de Desarro- } \\
\text { llo Comunal (ADESCO) }\end{array}$ & $\begin{array}{l}\text { Proyectos para el desarro- } \\
\text { llo social, mejoras en la } \\
\text { calidad de vida. Cargos } \\
\text { electos por personas aso- } \\
\text { ciadas. }\end{array}$ & $\begin{array}{l}\text { Mujeres y Hombres } \\
\text { De predominio } \\
\text { hombres. }\end{array}$ \\
\hline
\end{tabular}




\begin{tabular}{|l|l|l|}
\hline Asambleas Comunitarias & $\begin{array}{l}\text { Se brindan conocimientos } \\
\text { a la población relaciona- } \\
\text { dos con avances o retro- } \\
\text { cesos en salud. }\end{array}$ & $\begin{array}{l}\text { Mujeres y hombres } \\
\text { boordinación hom- }\end{array}$ \\
\hline
\end{tabular}

Fuente: elaboración propia.

Tabla 4: Significados, valoraciones y motivaciones

\begin{tabular}{|c|l|l|}
\hline $\begin{array}{c}\text { Significados, } \\
\text { valoraciones, } \\
\text { motivaciones }\end{array}$ & $\begin{array}{c}\text { Perfil de las personas } \\
\text { y explicación de la } \\
\text { subcategoría }\end{array}$ & $\begin{array}{c}\text { Citas que reflejan } \\
\text { el resultado }\end{array}$ \\
\hline Reconocimiento social & $\begin{array}{l}\text { Se manifiesta en mujeres } \\
\text { y hombres. Los hombres } \\
\text { particularmente recalcan el } \\
\text { impacto que tiene en su } \\
\text { imagen. Las personas co- } \\
\text { bran importancia en la di- } \\
\text { námica social y se sale del } \\
\text { anonimato. Es un sentimien- } \\
\text { to compartido por parti- } \\
\text { cipantes de todos los } \\
\text { espacios. }\end{array}$ & $\begin{array}{l}\text { Contraloría Social en } \\
\text { el sentido (que) prime- } \\
\text { ro tenemos reconoci- } \\
\text { miento a nivel del } \\
\text { Ministerio de Salud... } \\
\text { El logro es la acepta- } \\
\text { ción que tenemos en } \\
\text { las comunidades". E10, } \\
\text { Mujer de 53 años. } \\
\text { "Cuando se consigue } \\
\text { un beneficio para toda } \\
\text { una comunidad se sien- }\end{array}$ \\
\hline
\end{tabular}




\begin{tabular}{|c|c|c|}
\hline & & $\begin{array}{l}\text { te bien uno, y que di- } \\
\text { gan ah pues por estar } \\
\text { en la directiva o por- } \\
\text { que anduvieron esto es } \\
\text { que se logró esto...". } \\
\text { E14, Hombre de } 34 \\
\text { años. }\end{array}$ \\
\hline $\begin{array}{l}\text { Afirmación de sí } \\
\text { mismo y de su uti- } \\
\text { lidad dentro del } \\
\text { grupo }\end{array}$ & $\begin{array}{l}\text { Las mujeres expresan cómo } \\
\text { la participación las proyecta } \\
\text { capaces e importantes para } \\
\text { el resto, las reafirma como } \\
\text { personas que contribuyen } \\
\text { al desarrollo de su comu- } \\
\text { nidad. La juventud refleja } \\
\text { esta autodeterminación en } \\
\text { sus discursos, el tener una } \\
\text { función dentro del grupo } \\
\text { crea un mayor sentido de } \\
\text { pertenencia. }\end{array}$ & $\begin{array}{l}\text { "Uno participando en } \\
\text { cualquier cosa, es para } \\
\text { que uno se oriente y diga } \\
\text { puchica esto me va ser- } \\
\text { vir... uno se siente como } \\
\text { que la gente como que } \\
\text { a uno más lo apoya, uno } \\
\text { siente de verdad que a } \\
\text { uno ayuda pues". E27, } \\
\text { Mujer de } 43 \text { años. } \\
\text { "Para mí la satisfacción } \\
\text { de ser útil a la sociedad } \\
\text { que es lo más importante } \\
\text { siento yo... no excluirse } \\
\text { uno solo, sino que per- } \\
\text { tenecery serle útil". E12, } \\
\text { Hombre de } 26 \text { años. }\end{array}$ \\
\hline
\end{tabular}




\begin{tabular}{|c|c|c|}
\hline $\begin{array}{l}\text { Legado histórico fa- } \\
\text { miliar y comunitario }\end{array}$ & $\begin{array}{l}\text { Se manifiesta en mujeres } \\
\text { y hombres. La importancia } \\
\text { del legado participativo se } \\
\text { expresa como la tradición } \\
\text { arraigada que se transmi- } \\
\text { te de generación en gene- } \\
\text { ración, se refieren mucho } \\
\text { a los recuerdos y al ejem- } \\
\text { plo que sus padres y abue- } \\
\text { los les dejaron. }\end{array}$ & $\begin{array}{l}\text { "Después de eso se deja } \\
\text { la lucha armada y noso- } \\
\text { tros siempre hemos se- } \\
\text { guido con una experiencia } \\
\text { organizativa con mujeres, } \\
\text { con jóvenes... dejamos } \\
\text { una lucha armada y nos } \\
\text { incorporamos a una lu- } \\
\text { cha política y social, don- } \\
\text { de había que exigir las } \\
\text { mejores condiciones de } \\
\text { vida, de salud, de edu- } \\
\text { cación para la población". } \\
\text { E10, Mujer de } 53 \text { años. }\end{array}$ \\
\hline $\begin{array}{l}\text { Ruptura de roles res- } \\
\text { trictivos socialmente } \\
\text { asignados }\end{array}$ & $\begin{array}{l}\text { Las mujeres, en su mayo- } \\
\text { ría se refieren a su trabajo } \\
\text { en participación como una } \\
\text { manera de romper con lo } \\
\text { que culturalmente se es- } \\
\text { pera de ellas. }\end{array}$ & $\begin{array}{l}\text { "[...] y también eso de } \\
\text { andar participando a mí } \\
\text { me ha ayudado en mi ho- } \\
\text { gar, porque en mi casa mis } \\
\text { hijos ellos hacen el oficio } \\
\text { en la casa, y si yo pasara } \\
\text { en la casa, solo yo lo hi- } \\
\text { ciera quizá, no tuvieran ese } \\
\text { nivel de conciencia". E20, } \\
\text { Mujer de } 33 \text { años. }\end{array}$ \\
\hline
\end{tabular}




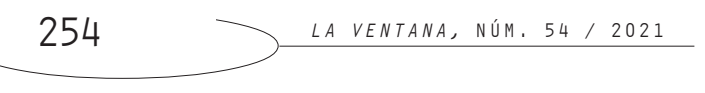

\begin{tabular}{|c|c|c|}
\hline $\begin{array}{l}\text { Aprendizaje y } \\
\text { capacitación }\end{array}$ & $\begin{array}{l}\text { Las mujeres manifiestan que } \\
\text { les permite adquirir cono- } \\
\text { cimientos que de otra ma- } \\
\text { nera no pudiesen adquirir, } \\
\text { generalmente por no tener } \\
\text { acceso a una formación por } \\
\text { el hecho de ser mujer. }\end{array}$ & $\begin{array}{l}\text { "[...] como decían que era } \\
\text { varón, él sí podía ir a la } \\
\text { escuela, el sí estudió, él } \\
\text { sabe leer bien, nosotras } \\
\text { no, porque dijeron que } \\
\text { como éramos hembras no } \\
\text { ocupábamos letras... a mí } \\
\text { me dificulta bastante en } \\
\text { comité eso le molesta a } \\
\text { uno". E23, Mujer de } 46 \\
\text { años. }\end{array}$ \\
\hline $\begin{array}{l}\text { Búsqueda de bene- } \\
\text { ficios comunes comu- } \\
\text { nitarios }\end{array}$ & $\begin{array}{l}\text { Las personas expresan que } \\
\text { la necesidad los hace mo- } \\
\text { vilizarse en la búsqueda de } \\
\text { mejores condiciones de vida. } \\
\text { Con el propósito de mag- } \\
\text { nificar posibles beneficios } \\
\text { que repercutan de mane- } \\
\text { ra positiva, nace un esfuerzo } \\
\text { colaborativo. }\end{array}$ & $\begin{array}{l}\text { "La participación social } \\
\text { está enterada de cuáles } \\
\text { son sus necesidades en la } \\
\text { comunidad... está consien- } \\
\text { te también de que le van } \\
\text { a favorecer a él no sola- } \\
\text { mente individualmente } \\
\text { sino de forma colectiva...". } \\
\text { E2, Hombre de } 63 \text { años. }\end{array}$ \\
\hline $\begin{array}{l}\text { Búsqueda de poder } \\
\text { y construcción de } \\
\text { democracia }\end{array}$ & $\begin{array}{l}\text { Predominio en hombres. } \\
\text { Brinda la sensación de } \\
\text { poder a las personas. }\end{array}$ & $\begin{array}{l}\text { "Cuando usted no par- } \\
\text { ticipa no puede opinar, } \\
\text { ahí impuesto le hacen } \\
\text { las cosas a uno... cuan- } \\
\text { do usted tiene parte en } \\
\text { el poder usted habla y } \\
\text { tiene voz y voto para } \\
\text { decidiry proponer". E18, } \\
\text { Hombre de } 63 \text { años. }\end{array}$ \\
\hline
\end{tabular}

Fuente: elaboración propia. 
DISCUSIÓN DE RESULTADOS A

PARTIR DE LAS PRINCIPALES

INEQUIDADES DE GÉNERO

ENCONTRADAS

\section{DIVISIÓN DEL TRABAJO EN LA \\ PARTICIPACIÓN SOCIAL EN SALUD Y \\ LAS FORMAS EN LAS QUE SE \\ MANIFIESTA}

Se encontró una división del trabajo en los procesos

y las formas de la participación en salud entre hombres y mujeres. En general, las actividades de la participación se relacionan con los roles que se desarrollan en el hogar, donde el hombre cumple un rol de proveedor y esta función se traslada a su trabajo en la comunidad: él es generalmente quien maneja presupuestos, busca financiamiento y distribuye las inversiones de los grupos y aunque hay mujeres que también se encargan de estas actividades, los hombres predominan. Las mujeres también reproducen sus funciones tradicionalmente asignadas en el hogar, su rol de cuidadora de la familia se visualiza fuertemente en las actividades de colaboración en la participación. Esta división del trabajo dentro de la participación, obedece a los prejuicios relacionados al no cumplimiento de un determinado rol impuesto llamado "femenino" o "masculino" y tiene un peso importante en el 
actuar de las personas. De acuerdo a estas afirmaciones y respondiendo a su rol impuesto de cuidadora, se pasa de mujer cuidadora de la familia a mujer cuidadora de la comunidad y se ven involucradas en los "quehaceres comunitarios". De esta manera Renaturalizando (Esteban, 2003) la desigualdad social de las mujeres argumentando de alguna manera que las diferencias biológicas o psicológicas las inclinan hacia las labores de cuidado dentro de la participación, es importante remarcar el hecho que es producto de las inequidades de oportunidad para la participación y la presión social del cumplimiento de roles socialmente impuestos para evitar caer en nuevas explicaciones esencialistas de las diferencias entre hombres y mujeres en el ámbito del cuidado.

No sé cómo llamarle, pero las mujeres somos las que más participamos, los hombres más ajenos a esto usted va ver la mayoría de mujeres entre unas cincuenta mujeres habrán cuatro cinco hombres, entonces por eso yo creo que las mujeres a pesar de todo el trabajo doméstico todo lo que vivimos a diario, la responsabilidad como esposa como madre, entonces en medio de eso nos vamos involucrando en los quehaceres comunitarios, por eso si usted ve aquí las que más participamos somos mujeres. (E10, Mujer de 53 años) 
Yo sé que los comités (de salud) hay más mujeres, se tienen más confianza entre ellas, otras que necesitan la planificación que porque no le llega la promotora, todo esto siento que tiene que ser parte entre los comités (de salud), fomentando eso, que lo vayan haciendo. (Hombre de 34 años, E14)

A pesar de esto, las mujeres también ejercen puestos directivos en las organizaciones, especialmente en la alianza regional ARSAM y en los Comités de Contraloría Social y de Salud, coordinando redes organizativas a nivel departamental codo a codo con autoridades de salud del mismo nivel. En las asociaciones de desarrollo comunal generalmente son vocales o secretarias, siendo hombres los presidentes aun cuando su nivel académico es más bajo, pero en estas Organizaciones al ser de elección popular, los hombres cuentan con mayor reconocimiento social. En las organizaciones donde las mujeres sí ocupan puestos directivos, se realizan diversas acciones: propuestas de proyectos de ley, convocan marchas e impulsan alianzas regionales. Estas mujeres generalmente tienen un perfil característico, poseen una formación política de base y experiencias organizacionales que se remontan a muchos años atrás. La formación que se adquiere participando juega un papel determinante en el empoderamiento, el aprendizaje es transformador y liberador (Rodríguez Beltrán, 2009). 
[...] entonces la federación me ha dado esa oportunidad de formarme, tal vez no con un título académico, sino que tengo todas las experiencias así acumuladas sin tener el título, va, he pasado cursos de computación, de contabilidad, y no me dificulta por tener un grado bajo de escolaridad. (E1, Mujer de 38 años)

Las mujeres que tienen una alta participación en el Comité de Contraloría Social también realizan en sus territorios encuestas de satisfacción usuaria, movilización social, cierran paso de carreteras y se manifiestan en las calles, entregan cartas y solicitan audiencias, son acciones que las personas reconocen no solo como existentes sino como efectivas y que forman parte del proceso que llevan sus demandas. Estas acciones son utilizadas para hacer denuncias, para demandar prestaciones directamente a funcionarios del ministerio a nivel nacional o local, para exigir políticas públicas y leyes al gobierno central y a la asamblea legislativa.

Cuando hay necesidad de manifestarse, también vamos a las manifestaciones, a la calle, exigiendo verdad que el médico, la enfermera, ver que trabaja, que les dé un buen trato a los pacientes. Y que el médico tenga más acercamiento con la gente, que le explique el porqué la enfermedad, el porqué del medicamento. (E05, Mujer de 49 años) 


LUZMILA TATIANA ARGUETA MONTERROZA
2. RUPTURA DE ROLES
RESTRICTIVOS SOCIALMENTE
ASIGNADOS A LAS MUJERES A
TRAVÉS DE LA PARTICIPACIÓN
SOCIAL EN SALUD

Las mujeres, en su mayoría, se refieren a su trabajo

en participación como una manera de romper con lo que culturalmente se espera de ellas, sobre todo cuando son madres y amas de casa dedicadas al trabajo doméstico. Participar es involucrarse en la esfera de lo público y no solamente en la vida privada. A través de la participación, la imagen de sí misma y su influencia en la dinámica de su familia cambia.

Me ayuda a mi autoestima, porque yo me siento bien andar participando, compartir con otras personas experiencias, eso le ayuda a uno personalmente, le ayuda a sentirse bien, contento, porque yo en la casa no me gusta estar en la casa, aunque yo sé que tengo trabajo (en la casa). (E20, Mujer de 33 años)

También fuera del hogar, pasa a ser alguien "importante",tanto para sus propios ojos como para los de su familia y comunidad. Le devuelve confianza y valor como persona y la empodera, retomando a Rodríguez Beltrán, (2009) que identifica como 
estrategias para el empoderamiento desde la dimensión psicológica cultural el abordaje de la autoimagen y la identidad, la posibilidad de redefinir reglas y normas de género y adquirir conocimientos para realizar actividades o metas que antes no pensaba realizar. Por ejemplo: se desenvuelven en actividades de liderazgo y organización, administración de recursos y formulación de proyectos, actividades que no habían tenido la oportunidad de desarrollar en esos ámbitos, ni la oportunidad de ejecución a nivel familiar y comunitario.

Para las mujeres que ejercen participación en salud, las relaciones de poder dentro del sistema patriarcal que conllevan subordinación hacia los hombres de su familia son determinantes. Las entrevistadas usan expresiones como "no les dan permiso", "las regañan", "a él no le gusta",etc. La mayoría de las mujeres considera el solo hecho de tener una pareja como un impedimento para realizar actividades de participación en salud. Las entrevistadas hablan de las restricciones que la figura masculina en su vida les impone para poder "salir" y "andar en la calle". Esta figura masculina dominante es la pareja, pero este fuerte vínculo de dominación masculina sobre la mujer también se expresa en el caso de no tener pareja, con la presencia de un hermano o el padre.

Yo estoy aquí sola, si yo estuviera con él no anduviera trabajando en las cosas así, en la comunidad, ni saliera quizás, porque solo estar en la casa, ni en 
una directiva no me dejara trabajar, es que no le gustaba. $Y$ ahora ahí me ve que yo salgo para donde yo quiero. (E11, Mujer de 58 años)

Otro rol que no siempre sufre una ruptura, más bien se extiende en horarios o a terceras, es el que las mujeres cumplen con su presencia en el hogar para hacerce cargo de las responsabilidades exclusiva de las mujeres, cuidado de las/os niñas/ os, adultos mayores e incapacitados, y por supuesto los quehaceres domésticos. Ambas dificultades son expresadas espontáneamente por todas las mujeres a la hora de contar sus experiencias de participación y, particularmente, no son mencionadas como obstáculos por los hombres. Ellas hablan de alargar las horas productivas del día para realizar sus labores en el hogar, iniciando de madrugada con los quehaceres, de forma que hacen evientes dobles y triples jornadas. GarcíaCalvente menciona cómo, a pesar de que las mujeres se involucran en ámbitos públicos, el trabajo de la vida privada no se minimiza, lo que repercute en la salud de las mujeres mismas o se "delegan" responsabilidades siempre en otras mujeres sin romper el ciclo (García-Calvente, Mateo-Rodríguez y Maroto Navarro, 2004, pp. 83-91). Lo que también se evidencia dentro de la participación de las mujeres, cuando algunas mujeres mencionan la figura de la abuela, comadre, vecina u otras figuras femeninas cercanas que son frecuentemente aludidas como la ayuda que les permite ejercer una participación activa, de 
modo que otra mujer aun sin ser de su familia, es quien da asistencia en sus tareas en este rol de ama de casa y madre. Es relevante mencionar cómo su trabajo con las comunidades y su participación en salud se ve condicionada al previo cumplimiento de su rol en el hogar, es decir, si no se cumple deberá forzosamente retirarse de la vida pública, como es el caso de algunas que mencionan haberse retirado por estas razones o cuando sus niños eran pequeños.

y me rogaron que me quedara (de directiva) y yo no les dije que no quería quedar, yo por estos niños, a veces le toca ir a reuniones uno, yo tengo dos niños chiquitos todavía. (E23, Mujer de 46 años)

[...] bueno a veces... (no participaba) porque como yo tenía los dos niños, mis hermanos, mi mamá pasaba solo enferma y a mí me tocaba todo el quehacer de la casa, todo me tocaba, de ahí cuando vine para acá sí, porque tenía mi niña, pero hay una vecina que ella me ayudó a mí, ella me ayudaba también, con mis niños. (E27, Mujer de 43 años)

Las asignaciones culturales y las imposiciones sociales de lo que es femenino también están inmersas en la cultura participativa de las personas por lo que, cuando ocupan cargos en alguna organización que demanden su tiempo fuera del hogar por 
más de un día, se presentan sentimientos de ambivalencia alrededor del trabajo en participación que a veces desincentiva a las mujeres a optar por cargos directivos y las empuja a elegir cargos en los que solamente es requerida una presencia local. Sánchez (2018) menciona que, aunque las mujeres se desarrollen en una vida profesional, sigue siendo buena madre la que dedica tiempo a cocinar a su familia, no ha desaparecido la presión de ser una madre sacrificada y que mantiene un hogar limpio, Sánchez afirma que esta presión repercute en la salud de las mujeres física y mentalmente.

Hay veces que llego a la casa y a veces que no, porque si uno tiene salidas y talleres y va estar semanas $y$ todo eso yo soy madre de tres hijos y gracias a Dios yo he tenido el respaldo de mi familia y me han apoyado que tengo a mi mamá y entonces ellos me han apoyado a que mis hijos pasen casi solo con ella pero sí al final yo me siento mal porque no se le puede dar el tiempo que los hijos requieren, pero también me siento bien como ya se lo expliqué en la forma en cómo he crecido bastante en conocimiento. (E1, Mujer de 38 años)

Participar les permite adquirir conocimientos que de otra manera no podrían adquirir, generalmente por no tener acceso a una formación superior formal y en algunos casos incluso básica. 
Las mujeres recalcan mucho la importancia de una formación que les permita participar de manera más efectiva, las capacitaciones que puedan recibir acerca de temas como contraloría social, organización comunitaria, formación de comités, elaboración de documentos, atención a enfermos y emergencias, primeros auxilios, etc. facilitan las distintas funciones que desempeñan desde su participación.

Las personas expresan cómo no solo les agrada aprender cosas nuevas, sino les da herramientas que mejoran su vida laboral, social y organizativa:

Siempre he andado sacando talleres de formación, nos hemos capacitado en contraloría social en las políticas públicas en salud, en las políticas públicas donde se pueda hacer contraloría a todas las instituciones públicas, he participado en talleres de formación donde se da el ciclo del proyecto, como se elabora un perfil técnico, entonces eso, andar involucrada en eso creo que me ha ayudado a mí llegar hasta donde ahorita estoy, más que todo lo hice por aprender, y así fue como yo me fui involucrando al final que ya me fue gustando estar metida en tantas cosas, y ahora pues ahora soy presidenta de la consultora de aquí del municipio, presidenta de la Asociación de mi comunidad, o sea tengo varios cargos y sigo siendo promotora voluntaria. (E11, Mujer de 48 años) 
Bastante reconocidas son las capacitaciones orientadas al empoderamiento de las mujeres y a la lucha contra las desigualdades de género, son consideradas primordiales para el fomento de la participación de mujeres. Muchas mujeres manifestaron reproducir las capacitaciones de género que distintas ONG imparten y gracias a ellas lograr mayor participación de las mujeres en cargos directivos y en presidencias de organizaciones predominantemente masculinas. Las mujeres en general manifiestan un interés por lograr la participación de otras mujeres, sobre todo jóvenes.

\begin{abstract}
Ahora ya tenemos mujeres que participan en cargos directivos, son presidentas de sus cooperativas no solo por estar ahí, también tienen capacidad de propuestas, entonces lo que nosotros hemos visualizado que para que la mujer ocupe espacio tiene que tener un proceso de formación porque solo así porque es socia de una cooperativa y quererla inducir que tiene que tomar esos cargos no se puede porque tiene que pasar un proceso de formación para que despegue y después se va adaptando y las cosas le van saliendo bien. (E1, Mujer de 38 años)
\end{abstract}

Existe una asociación de la participación con la liberación de lo impuesto, estar organizado es sinónimo de "no dejarse", de "no dejar que lo pasen a llevar", de potenciar la aptitud 
para ejercer personalmente un derecho y el cumplimiento de una obligación. Ese poder que como persona se ve aplastado cuando el sistema económico le impone subordinación hacia el mayor capital, cuando el sistema patriarcal le impone subordinación hacia los hombres. Entonces se busca una sensación emancipadora que les devuelve colectivamente la autodeterminación que el sistema mismo les despoja, para las mujeres la sensación emancipadora es aún más sentida cuando participar les brinda autonomía y las sitúa en posiciones de poder sobre sí mismas y sobre el grupo que representan, situaciones que frecuentemente les son negadas en el hogar y aún sobre sí mismas y su cuerpo (Lagarde, 2001).

\section{UN PUESTO EN LA MESA Y LA DEMANDA DE ESPACIOS DE PARTICIPACIÓN HORIZONTALES PARA LAS MUJERES}

La utilidad que una persona tiene para el resto de la comunidad se reafirma al participar en salud. El sentimiento de pertenecer y aportar a su comunidad de forma activa genera una satisfacción personal y autoafirmación. Las personas jóvenes en particular, reflejan esta autodeterminación en sus discursos. Este punto cobra vital importancia en la participación de las mujeres, para quienes ejercer su función como representantes de sus comunidades les devuelve 
un valor personal agregado donde encuentran que son valoradas fuera de la vida en el hogar. Es necesaria, entonces, una reeducación social que permita trascender los estereotipos de género, pero sobre todo brindar herramientas a las mujeres para vencer los obstáculos que se les imponen con mayor peso a la hora de ejercer ciudadanía. Según Morgan (2007) las mujeres relacionan su papel en la organización social, como una manera de encontrar "su lugar en el mundo", muy parecido a las expresiones encontradas en las mujeres de este estudio. Morgan enfatiza la importancia del empoderamiento en el propio universo simbólico y en la cultura política. De igual manera Rodríguez Beltrán (2009) dice que el empoderamiento no puede ser una mera transmisión de conocimientos o responder a un modelo motivacional, sino que supone un enfoque de cambio, de control de las personas y colectividades sobre sus propias vidas. Por lo anterior, "un puesto en la mesa" no necesariamente significa un real poder de incidencia. Esto sería, como menciona Lagarde, (2001) valorar equivocadamente la presencia de mujeres como si su mera presencia garantizara igualdad. La apertura facilita, pero no garantiza una transferencia de poder, para construir un modelo de participación democrático del que habla Cunill (2009) entre estado y sociedad civil; y mucho menos para construir una democracia genérica de la que habla Lagarde, donde se modifiquen y establezcan las relaciones democráticas entre géneros. 
En la participación social en salud existe un espejismo que se crea debido a la abundancia de las mujeres, pero que, a pesar de ser mayoría, están alejadas de puestos desde donde se toman las decisiones. Este es uno de los hechos que García Prince plantea como uno de los más significativos en la ilusión de igualdad, la visibilidad presencial de las mujeres en los espacios pese a una existencia de segregación que la mantiene excluida de donde simplemente no es aceptada (García Prince, 2006).

Las mujeres incluidas en el estudio que logran cargos directivos tienen un perfil muy diferente a los hombres en los mismos puestos. En la mayoría de los grupos, son los hombres quienes ocupan puestos de presidencias y directivos. Generalmente un hombre, cualquiera que sea su perfil (joven, viejo, casado, soltero, educación básica o técnica, etc.), llega a situarse en puestos que les permiten tomar decisiones de gran envergadura. Aún si tienen poca instrucción académica. En cambio, las mujeres que logran ocupar cargos directivos tienen en común ciertas características: han tenido estudios medios y/o superiores o complementado sus estudios de manera técnica, además, cuentan con formación política organizativa y generalmente muchos años de experiencia de trabajo con la organización social. Sin excepción, son mujeres que cuentan con apoyo familiar (generalmente su propia madre) para poder ausentarse del hogar y sus hijos ya han crecido lo suficiente para no necesitar su presencia constante. Por lo que 
ésta distribución de poder es desigual, inequitativa y responde a los patrones culturales de sobrevaloración masculina y subordinación femenina al hogar.

Se manifestó también que si se busca la participación de la mujer a través de asignación de cuotas para puestos directivos, se cubren con mucha dificultad. Esta dificultad está relacionada con inequidades de género más profundas: inequidades estructurales y culturales, como el acceso a la educación formal y a la autonomía económica, puntos que se abordan más abajo. En cambio, fue reconocido por las entrevistadas que las intervenciones en la comunidad directamente relacionadas al fomento del conocimiento y prácticas de la equidad de género inician a una apertura de la participación en salud hacia las mujeres y desde las mujeres para la participación. Estas intervenciones evitan que se limite la participación de las mujeres a las acciones asociadas al cuidado materno infantil y por el contrario las invitan a involucrarse, por ejemplo, al campo del desarrollo social, hasta el momento claramente masculino, o como muchas expresaron, las invita a animarse a postular a cargos directivos. Las intervenciones relacionadas a las prácticas de la equidad de género también abordan a las comunidades para un cambio en la visión de la mujer dentro de los procesos participativos comunitarios. 


\section{PROYECCIONES, AUTONOMÍA Y SOSTENIBILIDAD DE LA PARTICIPACIÓN SOCIAL EN SALUD}

La valoración del trabajo en participación social, está relacionada con los logros que se han obtenido (de los que han sido parte y de los que han sido históricamente adquiridos) y las proyecciones que se realizan también están basadas en estas experiencias exitosas. Esta valorización permite proyectarse de manera positiva y hasta ambiciosa en el futuro a corto, mediano y largo plazo en la participación y sus implicaciones. Dialécticamente, los logros validan su trabajo, fortaleciendo sus asociaciones y posicionándolas en su comunidad y ante la institución con fuerte reconocimiento social, proyectándolas nuevamente hacia incidencias mayores. Esta auto motivación es renovada por nuevos proyectos e incentivos, sin dejar de ser alimentada también por las historias personales, lo que va enriqueciendo estos procesos para su conservación, defensa y crecimiento a futuro.

Me siento satisfecha porque hemos tenido logros verdad, como alianza regional de salud de Morazán ARSAM o Comités de Contraloría Social en el sentido (que) primero tenemos reconocimiento a nivel del Ministerio de Salud, porque si nosotros enviamos una solicitud, una carta lo que sea, nosotros inmediatamente 
tenemos respuesta. Eso es uno de los logros, que haiga venido gente de nivel central a supervisar las unidades de salud, laboratorios, el hospital y todo eso, eso ha sido otro de los logros, verdad. El logro es la aceptación que tenemos en las comunidades cuando nosotros queremos dar una información, capacitación o lo que sea, esos son logros que se obtienen, yo creo que ha habido muchos más, la misma subsistencia de la ARSAM, de los comités, de todo eso, creemos que son logros importantes, que hemos logrado que haiga. (E10, Mujer de 53 años)

La sostenibilidad económica para la participación es identificada como un obstáculo por la mayoría de personas, los voluntariados para la participación disminuyen el tiempo de trabajo y por ende disminuyen mensualmente los ingresos familiares. La falta de recursos también toma una distinción de género: para los hombres está ligado a dejar de proveer o aún a pagar a quien realice su trabajo. Para las mujeres está relacionado a un tema no solo de proveer y perder ingresos para su familia al dedicar el tiempo a participar, sino un tema de ausencia de autonomía económica y violencia patrimonial. Esta condición vuelve su involucramiento en la participación dependiente a la "asignación de dinero y aprobación" que sus parejas (o la figura masculina dominante en su vida, jefe de hogar), les proporcionen para sus actividades fuera del hogar. 
La cooperación de las ONG facilita especialmente a las mujeres la posibilidad de involucrarse y participar a través de subsidios de transporte y alimentación, pero su intervención está limitada a la temporalidad de los proyectos existentes, sin abordar la limitación estructural de vulneración de sus derechos.

Digamos, mandan a Perquín a una reunión ya se ocupan un par de dólares, entonces hay veces que lo que uno tiene que programar, así su programación económica, tengo que ir a esta reunión y dejar de ir a tal parte. (E14, Hombre de 34 años)

La alianza no tiene fondos para difundir, para trabajar con la base o sea más que todo es coordinarlas, entonces las organizaciones como que, las ONG también tienen que tener esa parte de incidencia porque las ONG y las instituciones les llegan fondos donde también pueden trabajar con la base para hacer un trabajo más social para que la gente participe, para que la gente se motive va, lo otro es que la alianza mejor de los pocos recursos que se ha tenido por medio de FECANM y ASPS cada año elaboramos un plan de acción y de actividades que vamos a realizar y lo logramos ejecutar pues durante el año y al final vemos los resultados de lo que lo que logramos ejecutar de lo que nos dio y no nos dio. (E1, Mujer de 38 años) 


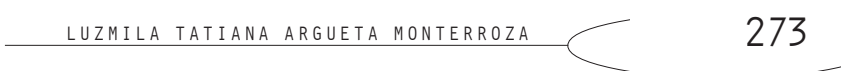

\section{CONCLUSIONES}

El ejercicio de la participación significa retribucio-

nes personales que involucran una afirmación de sí mismos como personas y su utilidad en el grupo al que pertenecen, lo que compensa la privación de poderes individuales por las macro estructuras económicas, políticas y patriarcales brindando una sensación emancipadora. Esta privación se agudiza en las mujeres que viven violencia de género en sus familias y comunidades, para las cuales la participación conlleva una sensación emancipadora del sistema, pero también una ruptura de los roles opresivos que le atañen, constituyendo su incursión en la vida pública un fuerte e importante significado de la participación.

Las intervenciones directas a través de capacitaciones y talleres en organización y contraloría social, pero sobre todo en equidad de género, se vuelven, según las mujeres entrevistadas, incluso más efectivas que la asignación de cuotas. La formación que la comunidad y la mujer reciben, la empodera para ejercer cargos directivos y la prepara para afrontar la violencia de género que existe dentro de las organizaciones, en su propia familia y con el personal de salud. Estas formaciones dirigidas hacia vencer las barreras de género que dificultan la participación de las mujeres, abre la oportunidad a que las mujeres se involucren en la vida política. 
La dificultad económica, concentrada en el gasto en transporte y alimentación, atribuible a la participación en salud, fue la principal dificultad manifestada, con el agravante de que para las mujeres que dependen económicamente de sus parejas, la asignación monetaria se les niega para limitar la vida pública que sus compañeros no aprueban, violentando de esta manera sus derechos ciudadanos. La contribución de las ONG en la sostenibilidad económica es buscada de manera directa por las organizaciones sociales, así, estos organismos adquirieren un reconocimiento popular en los territorios como facilitadores de procesos.

\section{Bibliografía}

Cunill Grau, N. (2009). Contraloría social y derechos sociales: El desafío de la integralidad. Gestión y Políticas Públicas, 1, 3-38. http:// mobile.repositorio-digital.cide.edu/handle/11651/2939

Esteban, M. L. (2003). Cuidado y salud: Costes en la salud de las mujeres y beneficios sociales. Congreso Internacional SARE Cuidar Cuesta: costes y beneficios del cuidado. Emakunde, Instituto Vasco de la Mujer. https://www.fuhem.es/media/cdv/file/biblioteca/Boletin_ECOS/ 10/Genero_y_cuidados.pdf

García-Calvente, M. del M., Mateo-Rodríguez, I. y Maroto-Navarro, G. (2004). El impacto de cuidar en la salud y la calidad de vida de las mujeres. Gaceta Sanitaria, 18(2), 83-92. http://scielo.isciii.es/ 

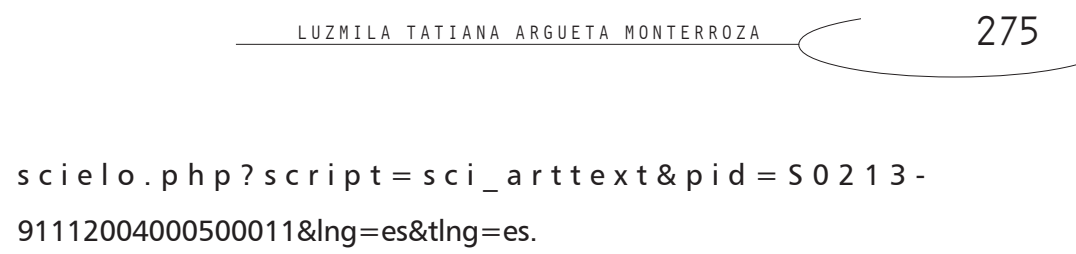

García Prince, E. (2006). El espejismo de la igualdad: el peso de las mujeres y de lo femenino en las iniciativas de cambio institucional. Otras Miradas, 6(1), 24-30. https://www.redalyc.org/articulo.oa?id=183/ 18360103

LagARDE, M. (2001). Las mujeres queremos el poder. Revista envío, (228). https://www.envio.org.ni/articulo/1067

Menéndez, E. L. (1995). Participación social en salud como realidad técnica y como imaginario social. Dimensión Antropológica, 5, 7-37. http:/ /www.dimensionantropologica.inah.gob. $m x / ? p=1499$

Ministerio de Saludos del gobierno de El Salvador. (2012). Política Nacional de Participación Social en Salud. Diario Oficial de la Republica de EI Salvador, (98), 53-85. http://asp.salud.gob.sv/regulacion/pdf/politicas/ politica_nacional_participacion_social_en_salud.pdf

Morgan, L. (2007). Sistematización de experiencias de participación ciudadana en Costa Rica y empoderamiento de mujeres (pp. 3-39). Costa Rica: Centro de Estudios y Publicaciones Alforja. http:// centroderecursos.alboan.org/sistematizacion/es/registros/1869sistematizacion-de-experiencias-de

Rodríguez Beltrán, M. (2009). Empoderamiento y promoción de la salud. Red de Salud, 14, 20-31. https://www.academia.cat/files/425-8234DOCUMENT/empoderamientopsmrodriguez.pdf

SÁNCHEZ, T. (2018). Políticas sanitarias e igualdad entre mujeres y hombres. Revista de Bioética y Derecho, (43), 179-192. http://scielo.isciii.es/ scielo.php?script=sci_arttext\&pid=S1886-58872018000200013 